\title{
SYMPOSIUM
}

\section{using facebook as an interactive learning environment in european political studies}

\section{sarah lieberman}

Department of Applied Social Sciences, Canterbury Christ Church University, North

Holmes Road, Canterbury, Kent, CT1 1QU, UK

E-mail: sarah.lieberman@canterbury.ac.uk

doi:10.1057/eps.2013.30; published online 7 June 2013

\section{Abstract}

Over the past decade, the use of web-based learning has increased, as has reliance on internet-based communication tools and learning environments. On the basis of a short study at Canterbury Christ Church University, this article will look at student use of Blackboard and the potential use of Facebook in higher education.

Keywords Facebook; Blackboard; pedagogy; virtual learning environment

I $\mathrm{n}$ recent years, the use of web-based learning has increased, as has reliance on internet-based communication tools and learning environments. Virtual learning environments (VLEs) are widely used in place of traditional notice boards and can host a large amount of additional information including lecture slides, course booklets, programme handbooks, reading lists and links to relevant websites; moreover, VLEs are now frequently used by staff in higher education as the primary means of communicating important information to students. Within the Politics and International Relations degree programmes at Canterbury Christ Church University, Blackboard is used as a VLE and students are expected to regularly consult this website to retrieve information posted there regarding general course and module issues. Blackboard also features an announcement and E-mail facility through which students are alerted to important information regarding timetabling, rooming and class structure and details regarding seminar tasks, assessments and hand in dates. Since the academic year 2011/ 2012, Blackboard has also been used to host turnitin, a 'work matching' programme that indicates possible plagiarism in student work. This means that student essays are submitted via a virtual drop box or 'bucket' embedded specifically onto the relevant Blackboard page. However, it has become increasingly clear that despite the high level of computer literacy among students, many fail to pick 
up important information from Blackboard and claim not to receive important E-mail alerts.

Since 2008, in the Politics and International Relations framework, 'Facebook' a popular social networking site (SNS) has also been used as an additional, and less formal, means of communication between staff and students. This was first initiated to advertise social and learning events forming part of an invited speaker series: Making Politics Matter. A Facebook page was created by students involved in organising these events, and it appeared to be largely successful. Observing this, it became clear that students communicate freely with each other using Facebook and on several occasions had attempted to communicate with staff members through Facebook. Although several staff members do use Facebook for personal communication, there was some reluctance to engage with students using this medium. The reasons for this were varied, but focused largely on privacy issues: many lecturers felt this would invade their own privacy, one felt strongly that he did not want to know about students' private lives, while two others have never used Facebook and did not wish to do so. However, despite some staff members' reluctance, it appears that Facebook may be a useful tool for staff/student communication and student learning.

On the basis of this observation, this article will outline a project I have undertaken over the past 3 academic years regarding Facebook use among students and its potential success as a learning tool. First, this project aimed to establish whether students consult Facebook more often, as often as or less often than they consult Blackboard and university-based E-mail accounts, and therefore whether I might be able to use Facebook to communicate important information regarding courses, lectures and work. Second, this project sought to discover whether Facebook might be used as an interactive

\section{'...Facebook may be a useful tool for staff/ student communication and student learning'.}

learning area where readings, newspaper articles and student comments might be posted.

This piece of work will combine methodologies to address the issues raised. First, a literature review will be carried out to ascertain whether a body of literature already exists on the use of SNSs for academic purposes. Second, I will discuss the research methods used in this project: survey material, both quantitative and qualitative, and comparative analysis, both quantitative - the length of time taken for students to reply to messages and threads on Blackboard and on Facebook, and qualitative - the quality of responses produced by students on each. In a third section, I will discuss my findings and analyse how these may inform my future teaching practice and evaluate whether the use of Facebook as an internet-based learning tool may positively impact on student communication and therefore enhance participation. This is a small-scale research project and the findings may not be generalisable. However, this study will hopefully lead to further research into the issues raised and to a clearer understanding of students' needs, and furthermore, will hopefully be of interest to faculty members posing similar questions.

\section{VLE VERSUS SOCIAL MEDIA}

The two communication systems that will be discussed in this article are Blackboard and Facebook. They have some similarities; that is, both are web-based communication tools: but they have significant differences; primarily, Blackboard is an institution-specific virtual learning area, 
or learning environment, that is unknown outside higher education; and Facebook is a global phenomenon with over 800 million users. Another important difference is that of business model: Blackboard is sold to universities as a tool with backup, support and guarantees regarding fitness for purpose. Facebook is funded through advertising, appeared on the stock market in May 2012 valued at US\$104 billion (Rushe, 2012) and provides no guarantees regarding the storage of saved material.

Parslow et al (2008) note that Blackboard is a university-based VLE provided by the institution for staff and students. Content on Blackboard is largely controlled by staff who must enrol users onto an area dedicated specifically to one module. This area provides a repository for course handbooks, module outlines, lecture slides, lecture and seminar information and postings about reading or other relevant information. Blackboard also provides an announcements board on which information can be posted relevant to the module in question, an E-mail facility through which staff can E-mail all registered users and an inbuilt e-portfolio tool incorporating blogging and wiki tools. Within the Politics and International Relations Framework at Canterbury Christ Church University, Blackboard is widely and successfully used with students. The repository and announcement functions are frequently updated by staff and regularly visited by (most) students. Other facilities on Blackboard have been trialled, but student uptake of blogs, wikis and other participatory aspects of the technology has been largely disappointing.

Facebook is a Web 2.0 application established in 2004 by, then, Harvard psychology student Mark Zuckerberg. Originally based on the idea of North American style 'yearbooks', Facebook first aimed only at Harvard undergraduate students. The phenomenon quickly spread to other Boston universities, all Ivy League universities and then all universities before becoming available to anyone with a registered E-mail address in 2006 (Phillips, 2007). According to Facebook's own statistics (Facebook, 2012), at the end of December 2011, it provided a service to 845 million monthly users and 483 daily users in 70 different languages around the world, and according to Special and Li-Barber (2011: 624), it is 'the second most trafficked site on the internet [and] the most visited social media site in the world'. Although it has now reached great proportions, Facebook's origin as an educational establishment communication tool is important, at least for us as lecturers, as students do continue to use it as a SNS within higher education institutions. Facebook has a number of different applications including instant messenger, a messaging service resembling E-mail, facility to post and store photographs, facility to set up and maintain 'groups' or pages for specific social groups and a personal profile for each member displaying a photograph, personal information and 'status updates' detailing members' activities, moods and observations. It also provides different levels of security and privacy for its members: members can choose to allow only 'friends' to access their profile, that is, preventing members of the public from viewing their profile; and members can reserve certain information for specific friends, that is, preventing access to certain information to other friends. Within the Politics and International Relations Framework at Canterbury Christ Church University, we have had limited experience of Facebook use with students, but see it as a potentially useful communication and interaction tool.

\section{USING FACEBOOK IN HIGHER EDUCATION}

This piece of work seeks to situate itself in a gap in the literature regarding the use

sarah lieberman european political science: 132014 
of Facebook in higher education. Given the recent increase in the usage of both VLEs and SNSs, the gap in the literature remains surprisingly large, and therefore this study cannot begin to claim to 'fill the gap'. However, an interesting literature base is emerging on the use of SNSs in universities, and more specifically on the use of Facebook as a pedagogic tool.

Teclehaimanot and Hickman (2011: 19) state that sites such as Facebook 'provide educators with new possibilities for reaching their students'. However, they go on to note that 'As these technologies are new, there is not a total understanding of how these technologies could best be used in education' (Teclehaimanot and Hickman, 2011: 19). Roblyer et al (2010: 137) discuss the potential uses of Facebook and other SNSs in higher education, suggesting that 'The growing popularity of SNSs indicates that by providing additional avenues and purposes for communications among students and faculty, social communications can become a contributor to successful learning'. They go on to suggest that 'SNS exchanges theoretically can be both a valid form of highlyinteractive instructional communication and an opportunity for pedagogical mentoring'. If this is the case, then the use of Facebook as a VLE has great potential.

Moving from pure pedagogic usage towards a blended pedagogic/social usage, McCarthy (2010: 729) discusses the use of Facebook with first year undergraduate students as a means to 'enhance the first year experience'. He notes that 'Facebook's intuitive interface and popularity makes it a very effective tool for developing "preliminary" relationships between all first year students as it negates key pitfalls such as language barriers and social inhibitions' (McCarthy, 2010: 730). His study is very interesting: in trials, McCarthy used Facebook as a platform through which work could be submitted, discussed and critiqued by students. During the first year of this trial, he found

\section{'...an interesting literature base is emerging on the use of SNSs in universities...'}

that although students engaged with the tasks, their friendships remained 'Embryonic': despite the use of Facebook, student friendships did not form offline, as they did online. During the second year of the trial, McCarthy extended the discussions to form a blended learning area in which ideas brought up on Facebook could be discussed in class. This, he found, worked well. He notes that 'Students were able to develop academic relationships freed from the constraints of the classroom and their own inhibitions, and over the semester discussions evolved from formal academic critiques to informal social interactions. The Facebook group facilitated peer interaction in the early weeks of the course when it was evident that such interaction would not take place in the classroom'. (McCarthy, 2010: 732).

However, both McCarthy (2010) and Roblyer et al (2010) note that there are potential downsides to use of social network sites in higher education. McCarthy notes that 'Facebook and other Web 2.0 technologies are not always appropriate or successful vehicles for formal teaching and learning activities. Some studies have suggested that the ways in which students use technologies in their everyday interactions with family and friends may often be different from their preferences for technology use in formal learning settings [and] ... that some students were resistant to the use of such technologies in the classroom' (McCarthy, 2010: 731). Similarly, Roblyer et al (2010: 138) point out that 'Of particular note is the significant difference between the perceived role of this tool as social, rather than educational'. Interestingly, however, Roblyer et al (2010: 138) suggest that 
'Students seem much more open to the idea of using Facebook instructionally than do faculty' (138).

\section{THE STUDY}

Despite the potential, highlighted problems that using Facebook with students could pose, I decided at the start of the academic year 2009/2010 to undertake a study of Facebook usage in the Politics and International Relations framework at Canterbury Christ Church University. This project continued during the academic year $2011 / 2012$. For the purpose of this study, I carried out three small-scale 'action research' experiments in 2009. I focused on one first year module EU: From Continent to Community, for which I was the module leader. This is a core module for all single honours Politics and International Relations students and all combined honours International Relations students. In 2009/2010, around forty students were enroled on this course, in 2011/2012 the course was taught to around eighty-five. I also discussed these issues with students taking a core second year module, Political Research and Practice, using this Facebook project to illustrate points regarding research ethics and survey writing. Early in the academic year, I told the students on both modules that I would be using Facebook as a communication tool on that particular module as an experiment that would form part of a research project.

The first task was to establish the ethics of the project and to ensure that the students involved were fully aware of the privacy issues that may be raised by the project. I stated in class that all information posted on Facebook would also be posted on Blackboard. This meant that if students did not want to be my 'friend' on Facebook, they would not be disadvantaged. I also stated that I had a dedicated Facebook account for work-related contacts and that students may wish to do the same to ensure that I would not be able to see any information regarding their private lives. I also acknowledged that different privacy settings exist on Facebook, and that they may wish to increase the privacy level they use for different friends. I felt that all these options gave students the opportunity to take part in the study, or not; to use their personal Facebook account, or not; and to raise their privacy settings so that I could not see their more personal information, or not. Once I had established my 'work' Facebook account, I asked students to send me a 'friend request' if they were willing to take part in the research. I was actually very surprised to see that all the students in this class did so, and not one of the students chose to set up a dedicated account for university business - all appeared happy for me to be able to see their photographs, personal information and status updates; as far as I am aware, no student blocked me from seeing any of their personal information. I was also interested to note that many students not involved in the research (i.e. those students not on the module I chose to work with) also sent me friend requests, suggesting that, in general, students are quite unconcerned who sees their personal information. This raises the interesting issue of whether we, as lecturers, should include sensible use of technology as one of the key graduate skills to be taught at university, and whether such issues should be included in our careers advice to students.

The second aspect of my research was a survey to ascertain the levels of use of Facebook and the levels of use of Blackboard. I used a variety of open and closed questions to gather both quantitative and qualitative data. Following Bryman's (2008) advice, in October 2009 I set a questionnaire to generate this data: I felt that this would be a suitable method of data collection as I had a closed sample to

sarah lieberman european political science: 132014 
survey and I assumed that I would be able to encourage all students present to respond in class. I was right, and I recorded 100 per cent response rate. Some questions were missed out, but all students surveyed responded to the majority of questions.

The survey findings were very interesting. Of the twenty-six students surveyed, 93 per cent used Facebook. Moreover, of that percentage, 58 per cent checked Facebook 'several times a day' and all used Facebook more than once a week. This compares favourably to the statistics for the university E-mail account: 19 per cent check this only once a week; 31 per cent once a day; 27 per cent twice a day; and 23 per cent several times a day; and very favourably to the statistics for Blackboard: 12 per cent checked Blackboard once a week; 62 per cent checked it once a day; 12 per cent check it twice a day; and 15 per cent check it several times a day. I carried out this research again in October 2011 as a point of comparison, this time with second year students. The results were similar: of the thirty-four students surveyed, thirty-three students stated that they used Facebook, with 65 per cent of these students claiming to check their Facebook accounts 'several times a day' and overall 88 per cent of the class checking more than once a day. This far exceeded the statistics for both the university E-mail account and Blackboard: the majority of students, 62 per cent and 59 per cent, respectively, checked these only once a day, with only 15 per cent of students consulting these sites 'several times a day'.

The third part of my research was an experiment to see how long it took for students to reply to a post on Blackboard and how long it took to reply to a post on Facebook. As my 'status update' on Facebook, I posted 'EU CONTINENT TO COMMUNITY STUDENTS: Feedback for your essays is now available to pick up from the Departmental Office. Please 'comment' here to confirm that you have received this information'. This was posted at 5.08pm: within an hour, five students had replied to say that they had received this information, and by the following morning another five had done so. Another seven students replied either by posting on my Facebook wall, or via personal message through Facebook. I posted the same message on Blackboard: 'EU CONTINENT TO COMMUNITY STUDENTS: Feedback for your essays is now available to pick up from the Departmental Office. Please email sarah.lieberman@ canterbury.ac.uk immediately to confirm that you have received this information'. I received no replies at all.

Finally, I asked students to complete part of a seminar task on Facebook; this involved searching for news stories on the European Union and pasting the link onto Facebook. This task was not well received; I was the only person to post any interesting news stories onto the specially created Facebook page. When I asked students why this had not worked, I received various replies including the following: 'I printed it out and brought it to class instead'; 'I read a lot but didn't remember to put it on Facebook'; 'Nothing happened that was interesting in Europe this week'; 'I would have done it if it was marked'; 'I didn't understand what we were meant to do'. One further piece of research was conducted largely by accident. Owing to a flood in one particular university building, we needed to make a last minute change to the lecture room. I announced this through Facebook and through Blackboard and discovered that almost all the students had received the information through Facebook, or via another student who saw it on Facebook. It seems that students are likely to check Facebook between every lecture, but are unlikely to check Blackboard or their university E-mail account more than once a day to pick up essential information. 
In the academic year 2011/2012, I took a slightly less involved approach to my use of Facebook with students, following Teclehaimanot and Hickman's (2011: 19) suggestion that 'Students find passive behaviours more appropriate than active behaviours'. During this academic year, I alerted students to the fact that I was carrying out research into the use of Facebook as an interactive learning tool and was invited by them to join an invite only Facebook group set up specifically for communication between Politics and International Relations students. This group had 100 members from across the 3 academic years and had managed to achieve, where my earlier attempts had failed, to act as a 'pinboard' for interesting political and international news stories and to provide a quick-fire question and answer mechanism. This use of Facebook appeared to positively facilitate communication between students. In a largely 'observational role', I remained a member of this group, posting only where I felt I could be useful, and this was well received. For example, one first year student posted on the wall of this page 'Does anyone know where you can find out the exact dates for our exams this summer?' I replied with a link to the relevant part of the university website and received the comment: 'oh thanks ... I didnt know you were on here!? Might use this more often!!' (sic), which I took to be a positive response to my contribution. There are, however, downsides to such usage of Facebook and I have seen several complaints regarding different members of staff, including myself! As this page was a studentinitiated, student-led and studentfocused Facebook group, I did not feel I should intervene, but I was pleased to note that several student did post that such comments were not appropriate given that staff were also members of the group.

\section{'...useful for imparting information quickly but that it was not quite as useful as an interactive learning tool'.}

\section{CONCLUSIONS}

This research into students' Facebook use has been very interesting, and useful. I found that within any given undergraduate class, over 90 per cent of students were members of Facebook and discovered that my statistics largely matched those collected by others. For example, Stutzman (2006) noted that 'Almost all of your institution's undergraduates are on the Facebook. I found that 94 per cent of UNC's freshman class was on the Facebook. Techcrunch reported in November that 85 per cent of all college students were on the Facebook, and surely that number has increased'. Moreover, he continues 'You can't fight numbers like this. More importantly, you can't ignore them' (2006). Personally, I found that Facebook was particularly useful for imparting information quickly, but that it was not quite as useful as an interactive learning tool. However, through observation I noted that students do use Facebook as an interactive tool, more successfully when they have instigated the usage themselves. The reasons for this might be found in the survey responses: when asked - what do you use Blackboard for mainly? - the responses were as follows:

Lecture rooms, course handbooks, changes to lectures, timetables, assignment info, checking important information, check and download Powerpoints, check announcements, read materials, rooming, downloading lecture slides, checking seminar information, reading material, updates, info from tutors, 
communication of events, submission dates, accessing email account, lecture notes, reading lists.

When asked - what do you use Facebook for mainly? the responses were as follows:

Keeping in contact with friends overseas, contacting friends, organising meetings, social networking, chat with friends, check news, post news, see what is going on, chat, meeting new people, distracting myself, sharing pictures, planning events and parties, to complain about things, talking to friends, planning events, links to websites, Making Politics Matter, talking to classmates, catching missed lectures, communicate about uni work, communicate with friends, upload photos, fun activities, keep in touch, getting to know new people in Canterbury, check inbox.

The survey responses suggest that students regularly use Facebook to receive and impart information and to keep in touch with friends. Students appear to see networking with classmates within this classification. However, the research indicates that it would take more work with the students for them to think of Facebook as a true learning environment: currently, it appears that group pages set up by lecturers pose little interest to students; and those set up by students are perhaps inappropriate arenas for participation by lecturers.
In terms of comparison between Blackboard and Facebook, both have clear advantages and disadvantages. Blackboard allows lecturers and staff to easily post and store course information; it provides a link to the University's E-mail system and can be administered by all staff with no fear of personal information compromise. However, despite claims to 'interactivity', the blog and wiki tools available through Blackboard seem difficult to use and have not been successful when used in coursework; and most importantly, students do not frequently check Blackboard. Facebook has the clear advantage of familiarity; students use it and all its functions regularly and skilfully. However, students may not be willing to use Facebook as an educational tool and if this is to be encouraged, certain parameters would need to be set to ensure staff and student privacy is maintained and protected. In conclusion, I can see a place for Facebook as a communication tool in the Politics and International Relations Framework at Canterbury Christ Church University, but my research has shown that it is difficult to achieve online interactivity with students through either Blackboard or Facebook. Further analysis of this issue and discussion with both staff and students regarding the use of Facebook and the inherent difficulties it poses regarding privacy, copyright and the safeguarding of material will need to take place before it is fully rolled out as the useful educational aid that it promises to be.

\section{References}

Bryman, A. (2008) Social Research Methods, Oxford: Oxford University Press.

Facebook. (2012) 'Fact sheet', Facebook, available at: http://newsroom.fb.com/content/default.aspx? NewsAreaId = 22, accessed 26 March 2012.

McCarthy, J. (2010) 'Blended learning environments: using social networking sites to enhance the first year experience', Australasian Journal of Educational Technology 26(6): 729-740.

Parslow, P., Lundqvist, K.Ø., Williams, S., Ashton, R. and Evans, M. (2008) 'Facebook \& blackboard: comparative view of learning environments', in SSE Systems Engineering Conference 2008, 25-26 September, The University of Reading, available at: http://centaur.reading.ac.uk/1105/, accessed 27 March 2012.

Phillips, S. (2007) 'A brief history of facebook', The Guardian, 24 July, available at http://www.guardian .co.uk/technology/2007/jul/25/media.newmedia, accessed 26 March 2012. 
Roblyer, M., McDaniel, M., Webb, M., Herman, J. and Witty, J. (2010) 'Findings on facebook in higher education: a comparison of college faculty and student uses and perceptions of social networking sites', The Internet and Higher Education 13(3): 134-140.

Rushe, D. (2012) 'Facebook narrowly avoids dip below starting price in mixed first day of IPO', Guardian Online 18 May, available at: http://www.guardian.co.uk/world/2012/may/18/facebook-mixed-dayipo-wall-street?intcmp $=239$, accessed 27 September 2012.

Special, W. and Li-Barber, K. (2011) 'Self-disclosure and student satisfaction with facebook', Computers in Human Behaviour 28(2): 624-630.

Stutzman, F. (2006) 'How university administrators should approach the facebook: ten rules', Fred Stutzman Blog: Thoughts about Information, Social Networks and Privacy, available at: http://fstutzman .com/2006/01/23/how-university-administrators-should-approach-the-facebook-ten-rules, accessed 27 March 2012.

Teclehaimanot, B. and Hickman, T. (2011) 'Student-teacher interaction on facebook: what students find appropriate', TechTrends 55(3): 19-30.

\section{About the Author}

Sarah Lieberman is Senior Lecturer in Politics at Canterbury Christ Church University. She has published articles on international moratoria; the IWC's whaling moratorium and the EU's GMO moratorium; the conflict between the United States and the European Union over GMOs; the impact on developing countries of GMOs; participatory decision making for biotechnology; and trade in genetically engineered commodities. 